\title{
Broken guide wire - a fault of design?
}

\section{[Le bris d'un guide métallique - un défaut de conception ?]}

Enrico Monaca MD, Stefan Trojan MD, John Lynch MD, Manfred Doehn MD, Frank Wappler MD

Purpose: To report a potentially serious complication resulting from a faulty guide wire during central venous catheterization.

Clinical features: We report breakage of a guide wire with potential severe implications for a 47-yr-old critical care patient. The tip of the J-wire became lodged in the internal jugular vein, and required fluoroscopic guidance for removal, which occurred without complication.

Conclusion: Breakage of a guide wire during central venous catheter insertion has been very rarely reported. However, inherent faults in design or in the manufacturing process of the guide wire could lead to this rare complication. A simple bedside test is proposed to detect breakage in the core section of the guide wire.

Objectif : Présenter une complication potentiellement dangereuse du cathétérisme veineux central résultant d'un guide métallique défectueux.

Éléments cliniques : Le bris d'un guide métallique s'est produit chez un patient de 47 ans des soins intensifs. La pointe d'un guide en J est demeurée logée dans la veine jugulaire interne et la fluoroscopie a permis de la retirer, sans complication.

Conclusion : Le bris d'un guide métallique pendant l'insertion d'un cathéter veineux central a été très rarement rapporté. Mais des défauts de conception inhérents ou relevant du processus de fabrication peuvent mener à cette rare complication. Un simple test de chevet est proposé pour détecter le bris dans la partie centrale du guide métallique.

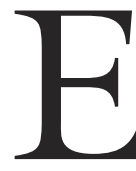
VERY year, more than 5 million central venous catheters are inserted in the United States. ${ }^{1}$ The reported rate of mechanical complications such as arterial puncture, air embolism, nerve injury and hemo- or pneumotho$\operatorname{rax}$ is between $5 \%$ and $19 \% .^{2,3}$ Catheterization of the superior vena cava is usually carried out using the method described by Seldinger., ${ }^{4,5}$ Under certain circumstances, breakage of the guide wire can occur with ensuing risk of foreign body embolism. This complication is extremely rare, with only a few case reports in the literature. ${ }^{6}$ Our case demonstrates that guide wire breakage is not necessarily due to handling mistakes, but may also be attributed to inherent design flaws or manufacturing errors. Consent for reporting of personal health information was obtained in accordance with our local institutional guidelines.

\section{Case report}

A 47-yr-old male intensive care patient (ASA III, body mass index 2l) suffered from an infected large tissue defect on the right lower leg sustained in an accident ten days previously. The past medical history included Crohn's disease which was inactive at that time. His ongoing management required central venous pressure monitoring.

A standard single-lumen central venous catheter set was used (Certofix ${ }^{\circledR M o n o}, 16 \mathrm{G}, \mathrm{B}$. Braun, Melsungen, Germany). The enclosed standard steel needle was used for puncture of the right internal jugular vein. Despite free aspiration of blood, the first attempt to insert the J-shaped end of the guide wire failed. A second attempt using the straight end of the guide wire was also unsuccessful. For both attempts, the guide wire could only be advanced a few millimetres beyond the tip of the needle, indicated by a black indicator on the wire. The needle and the guide wire were then removed together, and a second puncture

From the University of Witten/Herdecke Department of Anesthesiology, Hospital Cologne-Merheim, Köln, Germany. Address correspondence to: Dr. Enrico Monaca, Department of Anesthesiology, Hospital Cologne-Merheim, University Witten/

Herdecke, Ostmerheimer Str. 200, D - 51109 Köln, Germany. Phone: 0049-221-8907-13196; Fax: 0049-221-8907-3868;

E-mail: MonacaE@Kliniken-Koeln.de

Accepted for publication January 28, 2005.

Revision accepted April 24, 2005. 


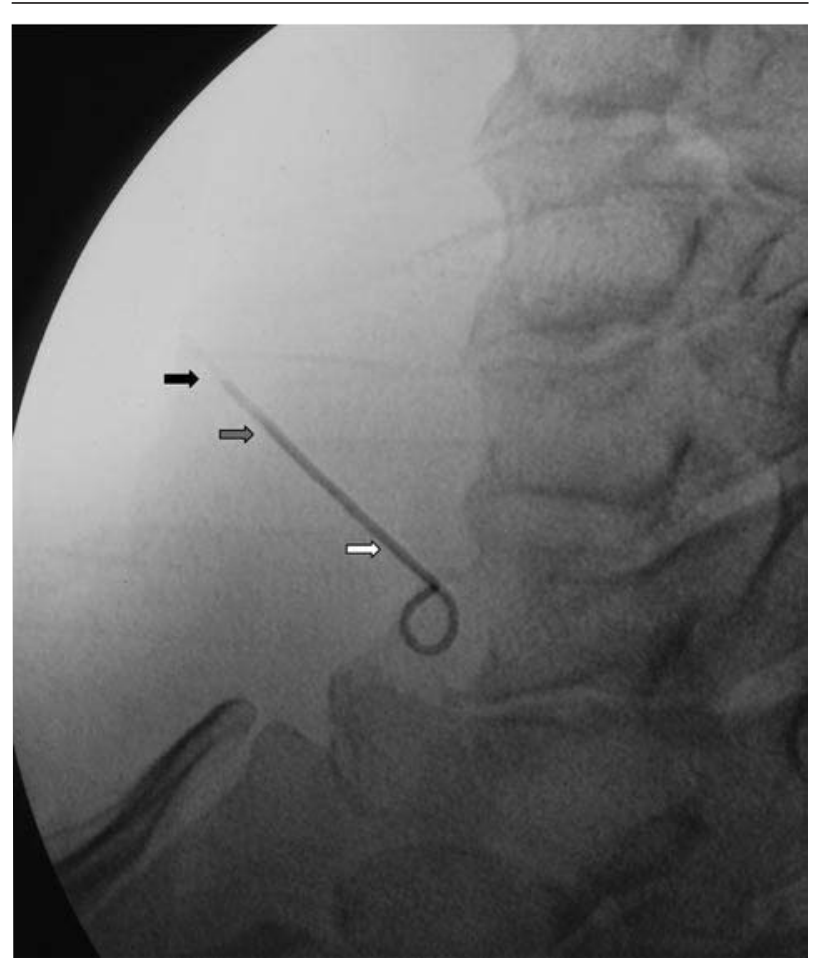

FIGURE $1 \quad X$-ray of the guide wire fragment in the right internal jugular vein.

$\Rightarrow=$ breakage site of the core portion; the other core fragment had been removed previously, as it is attached to the straight-tip end of the guide-wire

$\Rightarrow=$ initial of unravelling of the coil-like outer covering

$\Rightarrow=$ stretched portion of coil-like outer covering

at the same site was carried out. Free flow of blood was obtained, however, once again the J-shaped tip of the guide wire could not be inserted more than a few millimetres beyond the needle tip. On attempting to remove the steel needle and the guide wire together, a part of the J-shaped end of the guide wire remained in the patient's vein. The guide wire tapered to a single thin wire filament which could be identified as its stretched coil-like outer covering. The inner core section could not be seen. Considerable resistance was felt on attempting to remove the guide wire. Continuous careful traction only led to further stretching of the outer covering with no sign of the intravascular fragment. In order to avoid complete breakage of the guide wire, further careful attempts at removal were carried out using an $\mathrm{x}$-ray image intensifier (C-Arm Exposcope Ziehm 8000, Ziehm Imaging, Nuremberg, Germany; Figure 1). With the help of the image intensifier, it was possible to extract the remain-

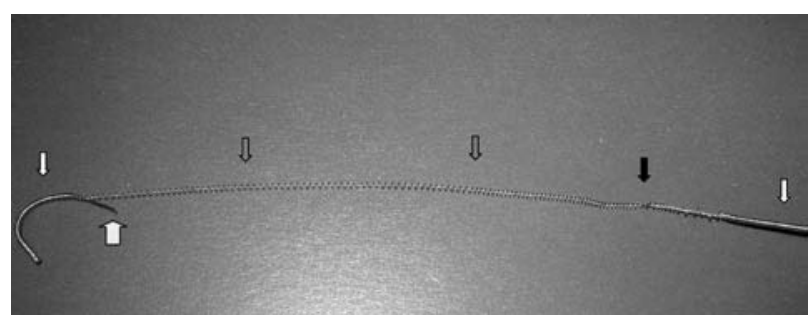

FIGURE 2 Reconstruction of the guide wire damage using an identical guide wire for demonstration purposes.

$\Rightarrow$ = intact guide wire coil-like outer covering

$\Rightarrow=$ a protruding part of the broken core at the J-shaped end

$\Rightarrow=$ stretched outer covering as described near the puncture-site

$\Rightarrow=$ the corresponding distal part of the broken core which is welded at the straight end of the guide wire

ing fragment of the guide wire without the use of auxiliary devices and without serious complications.

Examination of the intravascular catheter fragment revealed breakage of the core wire immediately proximal to the J-shaped tip. While the outer covering of the guide wire was intact at the J-shaped tip, further on, its coil-like structure became unravelled like an overstretched spring. The longer broken core fragment welded to the straight-tip end of the guide wire had been removed initially, before the stretching process began. Unfortunately, the outer covering was so deformed after removal that a meaningful demonstration was no longer possible. However, another identical guide wire was prepared in such a manner to depict the exact circumstances of the original incident (Figure 2).

\section{Discussion}

To understand the etiology of this rare complication it is necessary to outline some features of the design and manufacture of the guide wire (TFX-Medical, Portadown, Northern Ireland) used in this patient. The guide wire consists of two parts: an inner single filament wire core and a surrounding wire-cover, which is coiled to form a spiral covering with elastic properties. This outer cover is designed as a helix of stainless steel which forms a central tunnel. The core wire is placed within this tunnel. In the model used, the outer covering is welded to the inner wire core at both ends. Apart from these two points, there is no further point of attachment between the core and the outer wire. Approximately $2.5 \mathrm{~cm}$ from the tip of the 


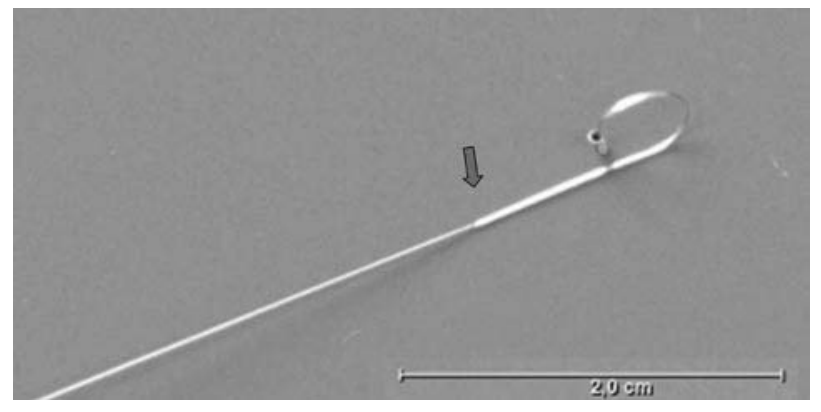

FIGURE 3 The core of a guide wire at its J-shaped end. A small portion of the outer covering at the tip was retained. The beginning of the flat section is marked by an arrow.

core at its J-shaped end, the round core is flattened to a thickness of $0.1 \mathrm{~mm}$, resulting in the typical curvature of the J-shaped part (Figure 3). However, the increased flexibility of the J-shaped tip is gained at the expense of a potential area of structural weakness at the junction of the rounded and flattened segments, leading to potential breakage.

The etiology of this complication must lie either in faulty design or manufacture, or in failure of the clinicians to adhere to the instructions for use. An inherent weakness at the beginning of the flattened J-shaped end of the core section remains a possibility. According to the manufacturer's test records, the stability of the guide wire is routinely examined at certain tension loads. The weld seams of the outer covering at both ends are supposed to withstand a pull strength of at least $17 \mathrm{~N}$ (1.73 kg force) before they detach from the core. In its middle section, the complete guide wire withstands stress of approximately $290 \mathrm{~N}(29.57$ $\mathrm{kg}$ force), (Personal communication, H.G. Wiegel and C. Reiche, B. Braun Hospital Care, Melsungen, Germany). Damage to the guide wire due to the cutting bevel of the accompanying puncture needle cannot be fully excluded, but is only likely if deliberate excessive force is applied. The fact that the J-shaped tip was extended twice just a few millimetres beyond the bevel of the needle, implies potential trauma to the wire. However, even in the case of a target fracture point, such as a kink, the wire could not be easily cut over a sharp edge. This suggests that an intact guide wire was unlikely to have been damaged by relatively small forces during a central venous catheter insertion. In this case, the breakage of the inner part of the wire, and not the coil-like outer covering, could exclude an effect by the needle bevel.

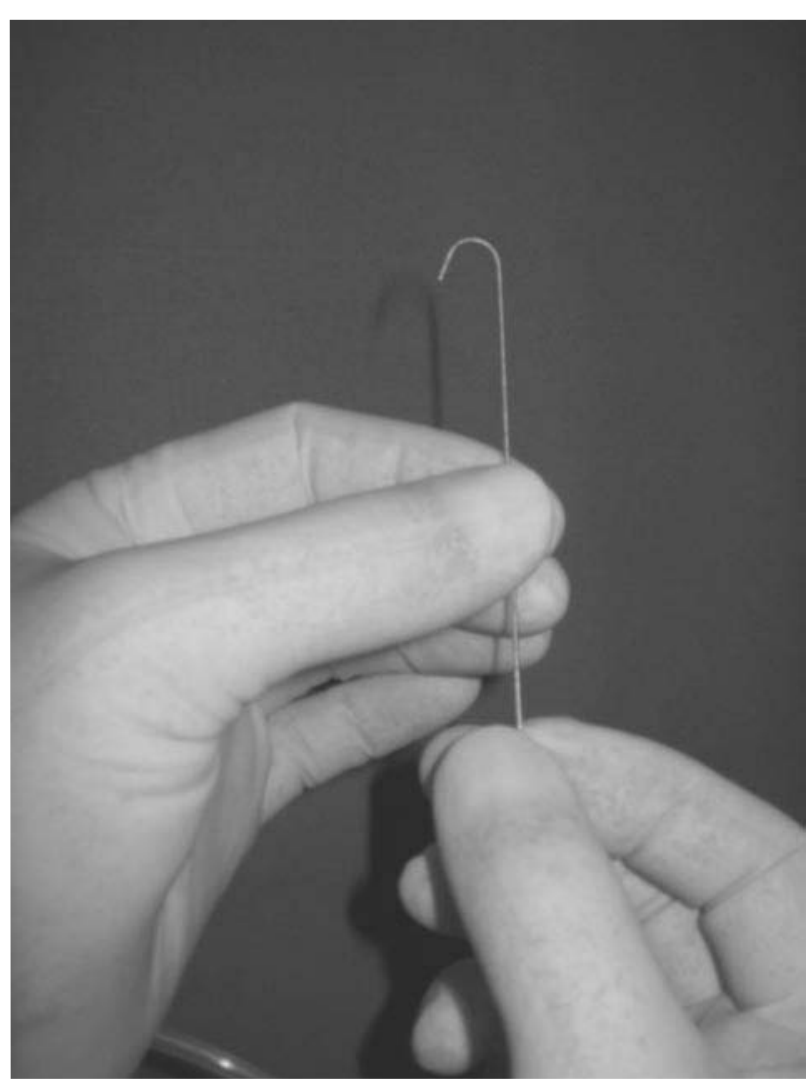

FIGURE 4 The guide wire is firmly held between thumb and forefinger of both hands.

Secondly, some of the maneuvers described in the case report might have potentially damaged the guide wire. ${ }^{6}$ In case of difficulty in advancing the J-shaped end, the manufacturer states that "[...] it can be of help to $[\ldots]$ insert the straight guide wire tip".$^{7}$ Retracting the guide wire "[...] very carefully $[\ldots]$ " through the needle is also permitted. ${ }^{7}$ However, breakage of the core or its detachment from one of the two welding points occurred even in the case of insertion without any complications. ${ }^{8}$ The fact that the core of the guide wire broke at the junction as described above, would seem to implicate material weakness or fatigue.

To detect breakage of the core portion of the guide wire, the following simple bedside test is proposed. If the outer covering of an intact guide wire is pulled carefully in opposite directions, the J-shaped end would be straightened (Figures 4 and 5). In comparison, an interrupted core would not resist this movement, resulting in an uncoiling and stretching of the outer covering. This test is simple and practical, but will of course, require validation through clinical investigation. 


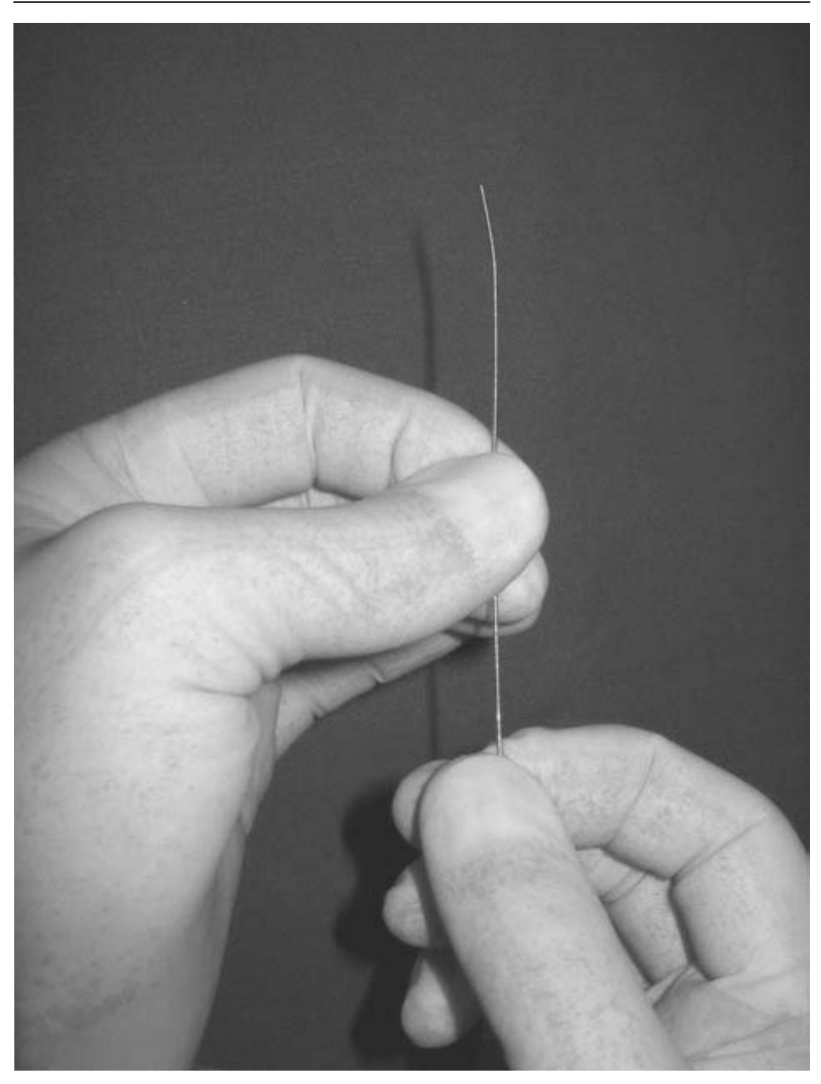

FIGURE 5 Both hands move in opposite directions until the J-shaped tip is straightened.

In conclusion, inherent design faults or manufacturing problems may contribute to guide wire failure, and potential embolization during central venous catheterization. Awareness of this problem, and adherence to simple steps may help prevent serious complications.

\section{Acknowledgements}

We thank Dr. Brockmann and Dr. Prange for technical support for Figure 2.

\section{References}

1 Raad I. Intravascular-catheter-related infections. Lancet 1998; 351: 893-8.

2 Sznajder JI, Zveibil FR, Bitterman H, Weiner P, Bursztein S. Central vein catheterization. Failure and complication rates by three percutaneous approaches. Arch Intern Med 1986; 146: 259-61.

3 Merrer J, De Jonghe B, Golliot F, et al; for the French Catheter Study Group in Intensive Care. Complications of femoral and subclavian venous cath- eterization in critically ill patients. A randomized controlled trial. JAMA 2001; 286: 700-7.

4 Seldinger SI. Catheter replacement of the needle in percutaneous arteriography. A new technique. Acta Radiol 1953; 39: 368.

5 Sternbach $G$. Sven Ivar Seldinger: catheter introduction on a flexible leader. J Emerg Med 1990; 8: 635-7.

6 Schwartz AJ, Horrow JC, Jobes DR, Ellision N. Guide wires - a caution. Crit Care Med 1981; 9: 347-8.

7 Manufacturer's instructions for use. Central venous catheter for infusion therapy. B. Braun Melsungen AG, Melsungen, Germany. February 2002.

8 Shimamoto T, Arai T. Breakage of a Seldinger spring guide wire during percutaneous catheterization of a subclavian vein (Japanese). Masui 1997; 46: 376-8. 